increasingly migrates to health systems, imposing lower costs on sponsors or researchers, hospitals have strong incentives to take on research projects that may not be in the best interests of the patients or the institution as a whole. Yet it is far from clear that the resources of clinical ethics are particularly apt for addressing these kinds of problems of structural adjustment or professional "deformation." ${ }^{4}$ The language of ethics risks being used to ratify decisions made for reasons of pragmatism or expediency. Institutions may find it more useful to set up ethics committees more to satisfy foreign partners' or research sponsors' requirements, rather than to address problems of concern to patients.

Ethics committees can serve many useful functions: education, dispute resolution, regulation, policy development. To be genuinely useful to clinicians and patients, and to be morally legitimate, ethics committees need to have both a clear sense of purpose and a clear sense of how best to achieve that purpose. Medical ethics scholars must take up the challenge of addressing the moral problems of social transition, otherwise they will be merely a moral figleaf covering the structural violence in countries in transition. ${ }^{5}$

Competing interests: None declared.

1 Borovečki A, ten Have H, Orešković S. Ethics and the structures of health care in the European countries in transition: hospital ethics committees in Croatia. BMJ 2005:331:227-9.

2 Slowther A, Johnstone C, Goodall J, Hope T. Development of clinical ethics committees. BMJ 2004;328:950-2.

3 Royal College of Physicians. Ethics in practice. London: Royal College of Physicians, 2005 .

Physicians, 2005.
Dwyer J. Teaching global bioethics. Bioethics 2003;17:432-46.

5 Farmer P. Pathologies of power: health, human rights, and the new war on the poor. Berkeley: University of California Press, 2005.

\title{
Commentary: Ethics in health care and research in European transition countries: reality and future prospects
}

Ana Marušić

Croatian Medical Journal, Šalata 3, HR-10000 Zagreb, Croatia

Ana Marušić editor

marusica@mef.hr
Borovečki et al examined the structure and performance of hospital ethics committees in Croatia, as a paradigm of healthcare ethical regulations in transitional countries. ${ }^{1}$ They found out that these bodies were highly bureaucratic and concerned almost exclusively with approval of research protocols, and that their members were mostly older physicians without the knowledge and skills that would be useful for the other functions of the ethics committees (education, guidelines development and ethical case analysis).

The same legalistic and bureaucratic organisation is a characteristic of the whole legal regulation of health care and health professionals in a transitional country such as Croatia. ${ }^{2}$ It is thus not surprising that ethical regulations are taken lightly and that their breach is common. For example, cheating, as an example of unethical behaviour, is very common among medical students in Croatia. ${ }^{3}$ A study of attitudes towards cheating, involving economics students in Russia, Israel, the Netherlands, and the United States, showed good correspondence between students' perception of cheating and corruption in the society. In contrast with the United States and many Western countries, where cheating is considered unfair competition and is condemned, in former communist countries the governmental system was always a servant of the party and thus considered an enemy by most citizens. High cheating rates among students and their permissiveness towards cheating, as well as a lax approach to ethical norms in general, can be explained by socioeconomic laws: the less consistently a norm is observed in a society, the lower the cost incurred by an individual deviating from the norm. ${ }^{4}$ The universities and healthcare institutions alike have a set of norms which are similar to those in most developed democracies, but they are usually buried in the legal departments (and now in the intranet pages) of the schools and institutions, and there is little education or institutional enforcement of adherence to the norms. Even analysis into the system and quality assessment is often not welcome: when we published the results of our study on academic misbehaviour of medical students, ${ }^{3}$ some of our colleagues regarded it as "not a nice thing to say about our school."

So what can be done? Realistically, bureaucratic and dishonest behaviour cannot be completely eliminated before other sectors of the society improve. For countries joining the European Union, any change must come from within, as the countries that made up the "old" EU may not provide the best example. Bureaucratisation, the closed nature of academia, and self sustenance of academic communities are not restricted to small scientific communities in former communist countries. Favouritism or "inbreeding" at universities, defined as the percentage of teachers at a university who trained at the same university, is especially high in Portugal (91\%), Spain (88\%), Italy $(78 \%)$, Austria $(73 \%)$, and France $(56 \%)$, compared with the UK (5\%) and Germany $(1 \%){ }^{5}$ What the EU can do for its new members or in negotiations with future members is to insist not only on high ethical standards in medicine but also on their implementation. Only education and transparent regulatory actions can improve the integrity of both present and future doctors and promote responsible and trustworthy physicians as leaders of changes in society.

Competing interests: None declared.

1 Borovečki A, ten Have H, Orešković S. Ethics and the structures of health care in the European countries in transition: hospital ethics committees in Croatia. BMJ 2005;331:227-9.

2 Bošnjak D, Marušić A. Croatia: legal regulation of doctors. Lancet 2000; 356:1349-50.

Hrabak M, Vujaklija A, Vodopivec I, Hren D, Marušić M, Marušić A. Academic misconduct among medical students in a transition country. Med Educ 2004,38:276-85.

4 Magnus JR, Polterovich VM, Danilov DL, Savvateev AV. Tolerance to cheating: an analysis across countries. J Econom Educ 2002;33:125-35.

5 Soler M. How inbreeding affects productivity in Europe. Nature 2001;411:132. 